\title{
Prophylactic Antibiotics in Twin Pregnancies Complicated by Previable Preterm Premature Rupture of Membranes
}

\author{
Olivia Myrick, MD ${ }^{1}$ Sarah Dotters-Katz, MD ${ }^{2}$ Matthew Grace, MD ${ }^{2}$ Tracy Manuck, MD2 \\ Kim Boggess, MD ${ }^{2}$ William Goodnight, MD, MSCR ${ }^{2}$
}

\footnotetext{
${ }^{1}$ Department of Obstetrics and Gynecology, Columbia University, New York, New York

${ }^{2}$ Division of Maternal Fetal Medicine, University of North Carolina, Chapel Hill, North Carolina
}

Address for correspondence Sarah Dotters-Katz, MD, Division of Maternal Fetal Medicine, University of North Carolina, 3010 Old Clinic Building, CB 7516, Chapel Hill, NC 27599-7516 (e-mail: sarahdk@med.unc.edu).

Am J Perinatol Rep 2016;6:e277-e282

\begin{abstract}
Keywords

- multiple gestation

- PPROM

- previable preterm premature rupture of membranes

- twins

Objective This study aims to determine if antibiotics given for latency to women with twins and previable preterm premature rupture of membranes (PPROM) affect the duration from membrane rupture to delivery.

Methods A retrospective cohort study of twin pregnancies at a single center from 2000 to 2015 with previable $\left(14^{0 / 7}-22^{6 / 7}\right.$ weeks) PPROM was conducted. Women who were not candidates for expectant management or who elected for immediate delivery were excluded. Pregnancy complications, delivery data, and neonatal outcomes were compared between women who did and did not receive latency antibiotics. The primary outcome was latency.

Results Of 52 eligible women, 30 (64\%) elected expectant management; 17 women received antibiotics and 13 did not. No demographic differences existed between the groups. The median gestational age of rupture was 20 and 20.3 weeks in the antibiotic group and no antibiotic group, respectively. Median latency was 0.8 and 2.4 weeks in the antibiotic and no antibiotic groups correspondingly ( $p=0.21$ ). Overall, 58.8 and $23.1 \%$ of women who did and didn't receive antibiotics developed chorioamnionitis $(p=0.07)$. Perinatal mortality and maternal complication rates were high, though not different between the groups.

Conclusion Currently, even though in singletons with previable PPROM there is a recommendation to consider administrating antibiotics, in the setting of twins, no evidence exists to support this.
\end{abstract}

Preterm premature rupture of membranes (PPROM) occurs in 3 to $4.5 \%$ of pregnancies. It accounts for one-third of all preterm births and is associated with significant infant morbidity and mortality. ${ }^{1,2}$ Compared with singletons, twins have both a higher rate of PPROM and a shorter latency from the time of PPROM to delivery, suggesting the greater impact of PPROM on outcomes in twins.,

received

May 3, 2016

accepted after revision

July 8, 2016
DOI http://dx.doi.org/

10.1055/s-0036-1587324. ISSN 2157-6998.
Previable PPROM, defined as spontaneous ROM occurring between 13 and $23^{6 / 7}$ weeks' gestational age is rare, occurring in $1.37 \%$ of twin and $0.52 \%$ of singleton pregnancies. ${ }^{4} \mathrm{~A}$ retrospective cohort study reported that $43 \%$ of twins born following PROM at $<26$ weeks survive, but $83 \%$ of survivors had significant neonatal morbidity. ${ }^{5}$ This is in contrast to singletons, where though overall survival is comparable,
Copyright $\odot 2016$ by Thieme Medical Publishers, Inc., 333 Seventh Avenue, New York, NY 10001, USA. Tel: +1(212) 584-4662.
License terms

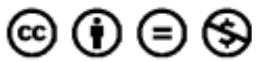


frequencies of long-term neonatal morbidity appear lower, 52 to $73 \%{ }^{6-8}$

In singletons with PPROM occurring between 24 and 34 weeks' gestational age, antenatal corticosteroids, neuroprotective magnesium sulfate (24-32 weeks' gestation), and prophylactic antibiotics are associated with improved neonatal outcomes. ${ }^{9,10}$ In addition, mothers carrying singleton gestations complicated by PPROM between 24 and 32 weeks' gestational age are typically offered prophylactic antibiotics (sometimes referred to as "latency" antibiotics), as this treatment increases the time between ROM and delivery by a median of 4 days and reduces perinatal morbidity. ${ }^{10} \mathrm{~A}$ recent guideline published by the American Congress of Obstetrics and Gynecology noted that there was inadequate data on the previable period to recommend the use of antibiotic to increase latency, but stated that it should be considered based on level $2 \mathrm{~B}-2 \mathrm{C}$ data. ${ }^{11}$ However, there is wide variation in the use of prophylactic antibiotics in the setting of the PPROM $<24$ weeks' gestation, and particularly among twins with PPROM $<24$ weeks' gestation.

The primary objective of this study was to examine the association between prophylactic antibiotic use at the time of previable PROM and latency time from PPROM to delivery in twins.

\section{Material and Methods}

This is a retrospective cohort study conducted at a singletertiary care referral center. Using the International Classification of Diseases codes of PPROM, PROM, and spontaneous abortion (634.0, 634.1, 634.7, 634.8, 634.9, 635.0, 635.1, $635.2,635.7,635.9,637.0,637.1,637.7,637.8$, and 637.9) all women from 2000 to 2015 with PPROM and twin gestation between $14^{0 / 7}$ weeks and $23^{0 / 7}$ weeks gestation were identified from the University of North Carolina (UNC) Women's Hospital delivery log and from billing records. Women were included if they had ruptured membranes without labor at between $14^{0 / 7}$ and $22^{6 / 7}$ weeks, carried multiple gestations, and elected expectant management of the pregnancy after PPROM. ROM was defined as documentation in the medical record of ROM confirmed by evaluation of history, physical examination, nitrazine or fern test, or intra-amniotic fluid injection of indigo carmine dye. ${ }^{12}$ The distinction between PPROM of twin Aversus twin B was made at the time of initial evaluation for PPROM based on which twin was presenting on ultrasound as documented in the admission note. For the purposes of this study, twin A was the presenting twin and twin B was the nonpresenting twin at the time of PPROM evaluation. Women who elected immediate delivery (via either induction of labor or dilation and evacuation), who had a contraindication for expectant management (e.g., suspected chorioamnionitis, active maternal hemorrhage), presented in labor (regular uterine contractions with progressive cervical change) or who had iatrogenic PPROM due to amniocentesis, chorionic villus sampling, or laser procedure for twin-twin transfusion treatment were excluded. Women who delivered both fetuses within 24 hours of PPROM or were missing delivery data were also excluded. We defined prophylactic antibiotics as antibiotics given specifically for the purpose of prolonging latency as documented in the medical record and that were started within 24 hours of membrane rupture. Prophylactic antibiotics were given at the primary clinician's discretion; type and dose of antibiotic choice, as well as timing and length of administration, was recorded. The study was reviewed and approved by the Institutional Review Board at the UNC at Chapel Hill.

We compared pregnancy outcomes among those with and without exposure to prophylactic antibiotics for PPROM. The primary outcome was duration from ROM to delivery of the twin A. Secondary outcomes included duration from ROM to delivery of the twin $B$, perinatal mortality (fetal or neonatal death before 28 days after delivery), neonatal morbidity (among survivors to neonatal intensive care unit discharge

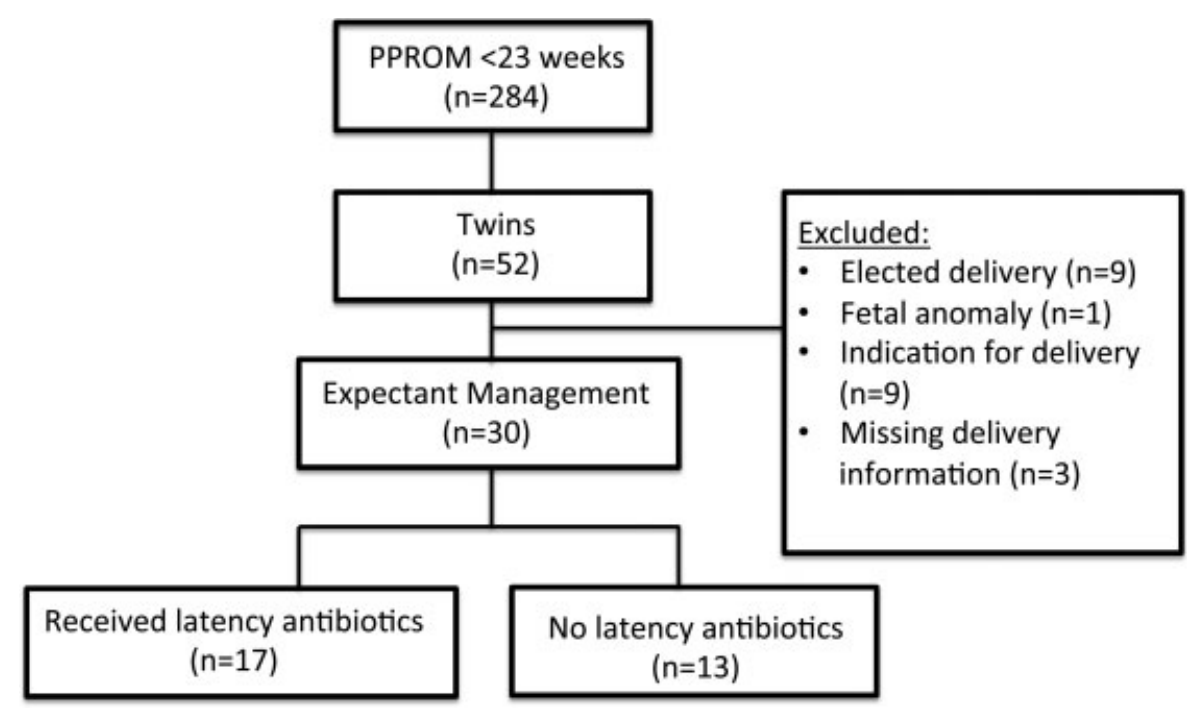

Fig. 1 Study population. 
composite of sepsis, bronchopulmonary dysplasia, pulmonary hypoplasia, necrotizing enterocolitis, and grade 3 or 4 intraventricular hemorrhage), and maternal morbidity (composite of intensive care unit admission, blood transfusion, sepsis, endometritis, hysterectomy, pulmonary embolism, deep vein thrombosis, wound infection, and readmission).

Bivariate analysis was performed with chi-square, Fischer exact test, or Mann-Whitney U test as appropriate. A log-rank test was used to analyze the effect of antibiotic exposure on latency to delivery for both twin A and separately for twin B, and a Cox hazard proportional ratio for antibiotic use and latency was calculated. Significance was set at $p<0.05$. Statistical analysis was performed using Stata software (version 14.0; Stata Corporation, College Station, TX).

\section{Results}

A total of 284 women were diagnosed with PPROM between $14^{0 / 7}$ and $22^{6 / 7}$ weeks at UNC Hospitals between 2000 and 2014. Of these, 52 (18.3\%) were twin gestations, and 30 of the 52 women met the inclusion criteria (-Fig. 1).

Of the 30 women, 17 (57\%) of 30 received prophylactic antibiotics; the remaining 13 (43\%) were managed expectantly
Table 1 Characteristics of women with previable preterm premature rupture of membranes and multiple gestation $(n=30,2000-2015)$

\begin{tabular}{|c|c|c|c|}
\hline & $\begin{array}{l}\text { Received } \\
\text { antibiotics } \\
n=17(\%)\end{array}$ & $\begin{array}{l}\text { No } \\
\text { antibiotics } \\
n=13(\%)\end{array}$ & $p$ Value \\
\hline Maternal age $(y)$ & $29.8 \pm 7.6$ & $32.3 \pm 5.2$ & 0.30 \\
\hline \multicolumn{4}{|l|}{ Race } \\
\hline Black & $5(29.4)$ & $5(38.5)$ & \multirow[t]{4}{*}{0.76} \\
\hline White & $9(52.9)$ & $8(61.5)$ & \\
\hline Other & $1(5.9)$ & 0 & \\
\hline Missing & $2(11.8)$ & 0 & \\
\hline Insurance (private) & $10(58.8)$ & 7 (53.9) & 0.13 \\
\hline Prior preterm birth & $3(17.7)$ & $4(30.8)$ & 0.67 \\
\hline Primigravid & $5(29.4)$ & $6(46.2)$ & 0.45 \\
\hline Tobacco use & $3(17.6)$ & $1(7.7)$ & 0.61 \\
\hline \multicolumn{4}{|l|}{ Chorionicity } \\
\hline Monochorionic & $5(29.4)$ & $2(15.4)$ & \multirow[t]{2}{*}{0.43} \\
\hline Dichorionic & $12(70.6)$ & $11(84.6)$ & \\
\hline
\end{tabular}

Table 2 Admission and delivery data for women with previable PPROM and multiple gestation $(n=30,2000-2015)$

\begin{tabular}{|c|c|c|c|}
\hline & $\begin{array}{l}\text { Received antibiotics } \\
n=17(\%)\end{array}$ & $\begin{array}{l}\text { No antibiotics } \\
n=13(\%)\end{array}$ & $p$ Value \\
\hline Median PPROM gestational age, wk, (IQR) & $20.0(19.0,21.9)$ & $20.3(17.3,21.6)$ & 0.45 \\
\hline ROM $<20$ wk gestational age & $7(41)$ & $6(46)$ & 0.99 \\
\hline \multicolumn{4}{|l|}{ Twin presenting with ROM } \\
\hline Twin A & $17(100)$ & $12(92.3)$ & \multirow[t]{2}{*}{0.43} \\
\hline Twin B & 0 & $1(7.8)$ & \\
\hline Subsequent ROM of twin $\mathrm{B}^{\mathrm{a}}$ & $2 / 17(11.8)$ & $3 / 12(25)$ & 0.62 \\
\hline Cervical dilation at ROM $(\mathrm{cm})^{\mathrm{b}}$ & $0.4 \pm 0.8$ & $1.4 \pm 1.6$ & 0.22 \\
\hline White blood cell count at PPROM ${ }^{a}$ & $13.6(11.5,14.6)$ & $11.9(10.6,16.2)$ & 0.60 \\
\hline Received at least one dose of antenatal corticosteroids & $6(35.3)$ & $4(30.8)$ & $>0.99$ \\
\hline Clinical chorioamnionitis & $10(58.8)$ & $3(23.1)$ & 0.07 \\
\hline Birth weight $A(g)^{c}$ & $594 \pm 318$ & $604 \pm 392$ & 0.82 \\
\hline Birth weight B $(g)^{c}$ & $703 \pm 493$ & $858 \pm 1,000$ & 0.92 \\
\hline \multicolumn{4}{|l|}{ Delivery mode $A$} \\
\hline Cesarean delivery & $4(23.5)$ & $2(15.4)$ & \multirow[t]{3}{*}{0.81} \\
\hline Vaginal delivery & $12(70.6)$ & $11(84.6)$ & \\
\hline Dilation and evacuation & $1(5.9)$ & 0 & \\
\hline Interval delivery attempted & $7(41.2)$ & $5(38.5)$ & $>0.99$ \\
\hline \multicolumn{4}{|l|}{ Delivery mode B } \\
\hline Cesarean delivery & $4(23.5)$ & $4(30.8)$ & \multirow[t]{3}{*}{$>0.99$} \\
\hline Vaginal delivery & $12(70.6)$ & $9(69.2)$ & \\
\hline Dilation and evacuation & $1(5.9)$ & 0 & \\
\hline
\end{tabular}

Abbreviations: IQR, interquartile range; PPROM, preterm premature rupture of membranes; ROM, rupture of membranes.

${ }^{a}$ Data only available from 18 women.

bData only available from 29 women.

'Data only available from 22 women (missing data from previable deliveries where infant weight not recorded). 
without prophylactic antibiotics. Of the 17 women, 13 women received a regimen of ampicillin 2 gm intravenous (IV) every 6 (q6) hours and erythromycin $250 \mathrm{mg}$ IV q6 hours $\times 48$ hours, followed by amoxicillin $250 \mathrm{mg}$ orally every 8 (q8) hours and erythromycin $333 \mathrm{mg}$ orally q8 hours $\times 5$ days. One patient each received: Azithromycin only for women with a penicillin allergy, Ampicillin/Sulbactam $1.5 \mathrm{~g}$ IV q6 hours $\times 48$ hours, ampicillin $2 \mathrm{~g}$ IV q6 hours and erythromycin $250 \mathrm{mg}$ IV q6 hours $\times 48$ hours only, and amoxicillin $250 \mathrm{mg}$ orally q8 hours and erythromycin $333 \mathrm{mg}$ orally q8 hours $\times 5$ days.

The antibiotic-exposed and unexposed groups were similar with regards to demographic and baseline characteristics, including maternal age, race, parity (including the history of preterm birth), and chorionicity (-Table 1). The median PPROM gestational age was also similar between antibioticexposed and unexposed pregnancies (20.0 vs. 20.3 weeks, $p=0.45$ ) (-Table 2). Other PPROM characteristics, including cervical dilation at time of initial evaluation following PPROM and total white blood count at the time of rupture, were also similar between groups (-Table 2). Of the 17, 10 (59\%) women who receive antibiotics developed clinical chorioamnionitis, compared with 3 (23\%) women who did not receive antibiotics $(p=0.07)$.

There were no significant differences in median gestational age at delivery for either twin A or twin B between two groups (-Table 2). Compared with no prophylactic antibiotics, use of antibiotic prophylaxis was not associated with a significant difference in median latency time from ROM to delivery for either twin A or B, though there may be a trend toward longer latency for those who did not receive antibiotics for twin A (-Fig. 2A) and twin B (-Fig. 2B).

Of the 30 women, 13 (43\%) women had maternal morbidity, 7 (41\%) who received antibiotics and 6 (42\%) who did not receive antibiotics, $p<0.99$. Two women developed sepsis before delivery, one in each group. Six women received a transfusion of at least one unit of packed red blood cells, four in the antibiotic group and two in the no-antibiotic group. Endometritis occurred in two women who received antibiotics and one who did not. The acute renal injury occurred in one woman who received antibiotics, and one woman who did not get antibiotics had a pulmonary embolism. Finally, there were no differences in perinatal mortality, neonatal morbidity, or maternal morbidity (-Table 3 ).

\section{Discussion}

In this study, use of prophylactic antibiotics in the expectant management of previable PROM in twins did not prolong pregnancy compared with no antibiotics. Maternal morbidity was high, regardless of antibiotic use, which should be considered when counseling women with previable PROM in twins. The majority (57\%) of women who elected to continue pregnancy received prophylactic antibiotics, despite data suggesting benefit or lack of harm.

Our findings should be considered in the context of previously reported data. There are some studies that suggest that the use of prophylactic antibiotics given in previable PPROM in singletons may improve neonatal outcomes and

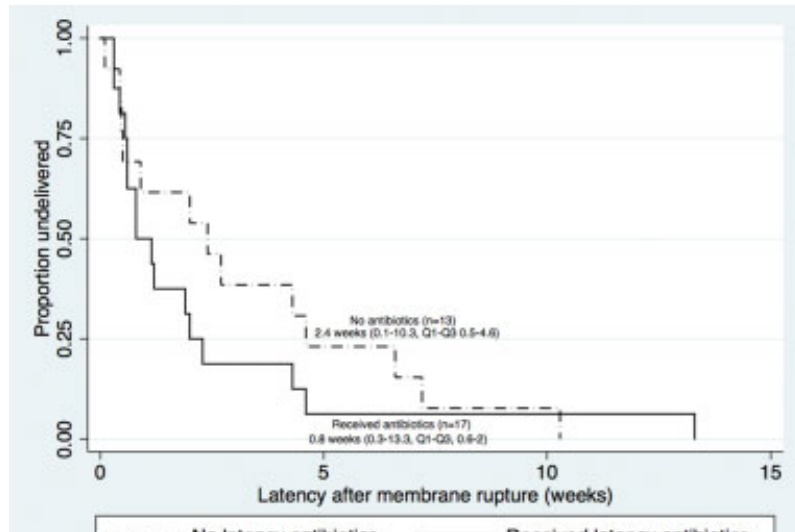

A
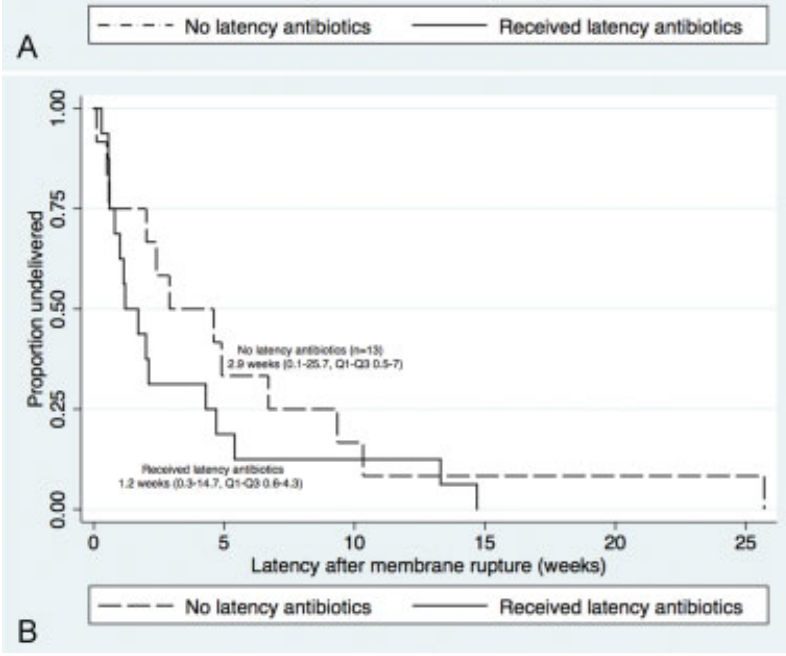

Fig. 2 (A) Duration of Latency of rupture of membranes for twin A. Kaplan-Meier curves showing latency after rupture of membranes by receipt of latency antibiotics $(n=17)$ compared with nonreceipt of latency antibiotics $(n=13)$. This figure compares duration of latency until delivery for twin A for pregnancies complicated by previable preterm premature rupture of membranes by use or nonuse of latency antibiotics at the time of membrane rupture. (B) Kaplan-Meier curves showing latency after rupture of membranes by receipt of latency antibiotics $(n=17)$ compared with nonreceipt latency antibiotics $(n=13)$. This figure compares duration of latency until delivery for twin B for pregnancies complicated by previable preterm premature rupture of membranes by use or nonuse of latency antibiotics at the time of membrane rupture.

other which describe the uses of antibiotics without specifically assessing the impact. ${ }^{13-17}$ In one study of 28 singleton pregnancies with previable PPROM, Xiao et al reported a significant neonatal survival difference (51 vs. $0 \%$ ) following prophylactic antibiotic use, though this was a retrospective study and antibiotics were given at clinician discretion. ${ }^{17}$ Others have reported a decreased frequency of chorioamnionitis with the use of antibiotics for periviable PPROM in singletons. ${ }^{18}$

Unfortunately, there is little data on the use of prophylactic antibiotics for PROM in twins. The ORACLE trial of antibiotics in PROM included 450 twins, and found no differences in delivery at 48 hours or 7 days, neonatal death, or major neonatal morbidities compared with no antibiotics. ${ }^{19}$ However, the number of twins with ROM at $<24$ weeks was not reported thus we cannot generalize this data to the previable twin PROM population. Limited data suggest that while singletons with previable PPROM have improved outcomes 
Table 3 Neonatal data for infants born from multiple gestation after previable PPROM $(n=30,2000-2015)$

\begin{tabular}{|c|c|c|c|}
\hline & $\begin{array}{l}\text { Received antibiotics } \\
n=17(\%)\end{array}$ & $\begin{array}{l}\text { No antibiotics } \\
n=13(\%)\end{array}$ & $p$ Value \\
\hline Median latency A, wk, (IQR) & $0.8(0.6,2)$ & $2.4(0.5,4.6)$ & 0.21 \\
\hline Median latency B, wk, (IQR) & $1.2(0.6,4.3)$ & $2.9(0.9,6.6)$ & 0.25 \\
\hline Perinatal mortality $(\mathrm{A})$ & $13(76.5)$ & 10 (76.9) & $>0.99$ \\
\hline Perinatal mortality (B) & $11(64.7)$ & $10(76.9)$ & 0.38 \\
\hline Median delivery gestational age A, (IQR) & $22.7(18.8,23.6)$ & $23(21.9,23.4)$ & 0.65 \\
\hline Median delivery gestational age B, (IQR) & $23.0(20.4,23.7)$ & $23.6(22.6,25.0)$ & 0.44 \\
\hline Maternal morbidity $^{a}$ & $7(41.2)$ & $6(46.2)$ & $>0.99$ \\
\hline Neonatal morbidity ${ }^{\mathrm{b}}(\mathrm{A})$ & $2 / 4$ & $1 / 3$ & $>0.99$ \\
\hline Neonatal morbidity ${ }^{\mathrm{b}}$ (B) & $1 / 6$ & $1 / 3$ & $>0.99$ \\
\hline Median delivery interval, wk, $A$ to $B,(I Q R)$ & $0(0,0.2)$ & $0.1(0,0.4)$ & 0.21 \\
\hline
\end{tabular}

Abbreviations: IQR, interquartile range; PPROM, preterm premature rupture of membranes.

ancludes: Intensive care unit admission, sepsis, acute renal injury, blood transfusion, endometritis, hysterectomy, deep vein thrombosis, pulmonary embolism, and readmission.

bInfants who were born at 23 wk or above and survived were included, includes: necrotizing enterocolitis, grade 3 or 4 intraventricular hemorrhage, bronchopulmonary dysplasia, pulmonary hypoplasia, and sepsis.

in an era of modern neonatal medicine, with survival in the range of 38 to $56 \%$ (but major morbidity in surviving neonates ranges from 52 to $73 \%$ ), though it is unclear if these improvements may be extrapolated to twin gestations. ${ }^{6-8}$ Wong et al examined the outcomes of 23 multifetal pregnancies complicated by PPROM $<26$ weeks' gestation and found $43 \%$ of twins survived, but only $17 \%$ survived without significant neonatal morbidity. ${ }^{5}$ It is, therefore, uncertain whether the use of prophylactic antibiotics in singleton pregnancies complicated by previable PPROM (a clinical problem to which there is no consensus, but more data than for twins) can be appropriately extrapolated to twin gestations.

The physiology of twins is different from singletons and thus interventions may not be applicable between these groups. For example, 17-hydroxyprogesterone for preterm birth (PTB) prevention is effective in singletons, but not twins in reducing recurrent PTB risk. ${ }^{20}$ The etiology of PROM may vary between twins and singletons, and thus prophylactic antibiotics may not be effective in twin previable PROM. Though not statistically significant, the trend toward longer latency in women who did not receive antibiotics, and the increased chorioamnionitis rate who did receive antibiotics, is concerning for the potential harm of prophylactic antibiotics in previable twin PROM. This study highlights the need for a differential clinical approach to twins compared with singletons.

Our study has limitations. As with any retrospective analysis, the study is subject to bias. The small sample size limits statistical power and our ability to assess the impact of certain variables such as prior preterm delivery. The high rate of perinatal mortality in the setting of twin PROM at $<24$ weeks limits our evaluation of prophylactic antibiotics on neonatal morbidities. Our small sample also prevents evaluation of prophylactic antibiotic use at different gestational ages. Additionally, one-third of our patients received an alternative antibiotic regimen, these varied in medication, dosage, and duration. This variation may have also contributed to the findings. The mean gestational age at PPROM was 20 weeks' gestation, thus latency of at least 3 to 4 weeks would be necessary to demonstrate impact on survival. In addition, several days of latency would be more clinically significant at a later gestational age, as there are significant survival differences when comparing PPROM at $<22$ weeks with $>22$ weeks. ${ }^{13,16,17}$ It is also possible that interventions that impact latency in PPROM may be gestational age dependent. Finally, we do not have long-term outcomes data to examine the true effect of antibiotics on surviving infants. A prospective multicenter trial specifically enrolling twins with previable PROM might help to clarify how these patients should be counseled and managed.

The management of twins with previable PPROM is widely debated with variability in clinical practice. Currently, there is no evidence for or against the use of antibiotics in previable PPROM for twin pregnancy. The Society for Maternal Fetal Medicine and American Congress of Obstetrics and Gynecology suggest consideration of latency antibiotics for previable PPROM from 20 to 24 weeks. ${ }^{11,21}$ Though we were underpowered to show a difference, our findings of no benefit with prophylactic antibiotic use in previable twin PROM and high rates of maternal morbidity, reinforce the importance of active counseling for women and families in this position.

\section{Source}

This study was performed at the University of North Carolina, Chapel Hill, NC.

Conflict of Interest

The authors report no conflict of interest. 
Note

These data were presented as a poster at the Infectious Disease Society of Obstetrics and Gynecology; August 6-8, 2015, Portland, OR.

\section{Acknowledgment}

None.

\section{References}

1 Gibbs RS, Blanco JD. Premature rupture of the membranes. Obstet Gynecol 1982;60(6):671-679

2 Meis PJ, Ernest JM, Moore ML. Causes of low birth weight births in public and private patients. Am J Obstet Gynecol 1987;156(5): 1165-1168

3 Bianco AT, Stone J, Lapinski R, Lockwood C, Lynch L, Berkowitz RL. The clinical outcome of preterm premature rupture of membranes in twin versus singleton pregnancies. Am J Perinatol 1996;13(3): 135-138

4 Mercer BM, Crocker LG, Pierce WF, Sibai BM. Clinical characteristics and outcome of twin gestation complicated by preterm premature rupture of the membranes. Am J Obstet Gynecol 1993;168(5):1467-1473

5 Wong LF, Holmgren CM, Silver RM, Varner MW, Manuck TA. Outcomes of expectantly managed pregnancies with multiple gestations and preterm premature rupture of membranes prior to 26 weeks. Am J Obstet Gynecol 2015;212(2):215.e1-215.e9

6 Dinsmoor MJ, Bachman R, Haney EI, Goldstein M, Mackendrick W. Outcomes after expectant management of extremely preterm premature rupture of the membranes. Am J Obstet Gynecol 2004;190(1):183-187

7 Manuck TA, Eller AG, Esplin MS, Stoddard GJ, Varner MW, Silver RM. Outcomes of expectantly managed preterm premature rupture of membranes occurring before 24 weeks of gestation. Obstet Gynecol 2009;114(1):29-37

8 van der Marel I, de Jonge R, Duvekot J, Reiss I, Brussé I. Maternal and neonatal outcomes of preterm premature rupture of membranes before viability [in English]. Klin Padiatr 2016;228(2):69-76

9 Rouse DJ, Hirtz DG, Thom E, et al; Eunice Kennedy Shriver NICHD Maternal-Fetal Medicine Units Network. A randomized, controlled trial of magnesium sulfate for the prevention of cerebral palsy. N Engl J Med 2008;359(9):895-905

10 Mercer BM, Miodovnik M, Thurnau GR, et al; National Institute of Child Health and Human Development Maternal-Fetal Medicine Units Network. Antibiotic therapy for reduction of infant morbidity after preterm premature rupture of the membranes. A randomized controlled trial. JAMA 1997;278(12):989-995

11 Obstetric Care Consensus No. Obstetric care consensus no. 4 summary: periviable birth. Obstet Gynecol 2016;127(6): 1184-1186

12 Simhan HN, Canavan TP. Preterm premature rupture of membranes: diagnosis, evaluation and management strategies. BJOG 2005;112(Suppl 1):32-37

13 Falk SJ, Campbell LJ, Lee-Parritz A, et al. Expectant management in spontaneous preterm premature rupture of membranes between 14 and 24 weeks' gestation. J Perinatol 2004;24(10):611-616

14 Fortunato SJ, Welt SI, Eggleston MK Jr, Bryant EC. Active expectant management in very early gestations complicated by premature rupture of the fetal membranes. J Reprod Med 1994;39(1):13-16

15 Grisaru-Granovsky S, Eitan R, Kaplan M, Samueloff A. Expectant management of midtrimester premature rupture of membranes: a plea for limits. J Perinatol 2003;23(3):235-239

16 Waters TP, Mercer BM. The management of preterm premature rupture of the membranes near the limit of fetal viability. Am J Obstet Gynecol 2009;201(3):230-240

17 Xiao ZH, André P, Lacaze-Masmonteil T, Audibert F, Zupan V, Dehan M. Outcome of premature infants delivered after prolonged premature rupture of membranes before 25 weeks of gestation. Eur J Obstet Gynecol Reprod Biol 2000;90(1):67-71

18 Morales WJ, Talley T. Premature rupture of membranes at $<25$ weeks: a management dilemma. Am J Obstet Gynecol 1993; 168(2):503-507

19 Kenyon SL, Taylor DJ, Tarnow-Mordi W; ORACLE Collaborative Group. Broad-spectrum antibiotics for preterm, prelabour rupture of fetal membranes: the ORACLE I randomised trial. Lancet 2001; 357(9261):979-988

20 Rouse DJ, Caritis SN, Peaceman AM, et al; National Institute of Child Health and Human Development Maternal-Fetal Medicine Units Network. A trial of 17 alpha-hydroxyprogesterone caproate to prevent prematurity in twins. N Engl J Med 2007;357(5):454-461

21 American College of Obstetricians and Gynecologists; Society for Maternal-Fetal Medicine. ACOG obstetric care consensus no. 3: periviable birth. Obstet Gynecol 2015;126(5):e82-e94 